\title{
The Organizational Modeling of a Supply Chain Management
}

\author{
Ech-Chelfi Wiame \\ Industrial Laboratory Techniques \\ FST, Sidi Mohammed Ben Abdellah University (USMBA) \\ $\mathrm{Fez}$, Morocco \\ El Hammoumi Mohammed \\ Industrial Laboratory Techniques \\ FST, Sidi Mohammed Ben Abdellah University (USMBA) \\ Fez, Morocco
}

\begin{abstract}
At the time of global competitiveness, the supply chain is of paramount importance in defining business strategies. Its architecture determines decision-making on the flow of material, informational and monetary flows. Its evolution, which depends on the dynamics of the market and the value proposition, leads companies to develop new forms of coordination. This, in order to have sufficient flexibility and responsiveness to respond favorably to demand,
\end{abstract}

The organizational complexity that arises from multi-enterprise operation requires appropriate methods, models and tools to describe study and improve design and management.

The purpose of this paper is to study the modeling approaches of a supply chain management and to propose models based on SADT and other conceptual approaches that make it possible to understand and master the inter-agent operation of the chain.

Keywords: SCOR, SADT, Organizational model, Analytical model.

\section{INTRODUCTION}

Companies face many decision-making problems related to the design and management of supply chains. The non-deterministic nature of the business environment forces decision-makers to use analytical tools to assess the performance of their organizations.

Globalization requires companies to respond favorably to personalized needs. These behavioral changes lead to an increased exchange of information between the actors (orders, forecasts, stock levels, delays, etc.) in order to study and analyze these structural and dynamic changes, it is necessary to model these networks of companies. The difficulties inherent in modeling the logistics chain are mainly due to the following causes [1] :

- The heterogeneity of the entities composing it

- The complexity of interactions

- Consideration of the environment

- The diversity of organizational structures

\section{MODELING OF A SUPPLY CHAIN MANAGEMENT}

Modeling a supply chain is to describe its structure and functioning to the study in order to improve its performance and competitive position. The modeling tools lead to the development of models, abstract representations of the system in discursive, graphic and sometimes formal form. Modeling tools developed in the field of business modeling are widely used to represent logistics chains [2]. Modeling is a process of representation that allows one to obtain an approximate image of the real system following an abstraction phase. This process facilitates the study and understanding of systems.

Modeling a system requires the definition of many simplifying assumptions. It is obviously not possible to describe in an identical manner the real environment.

Implementing a supply chain project requires companies to control their processes internally in order to understand their interactions externally. In this framework, multiple modeling approaches are used to describe and analyze the organization. A taxonomy of these models is presented in [1], the Fig.1 proposes a taxonomy composed of three large classes of models. 


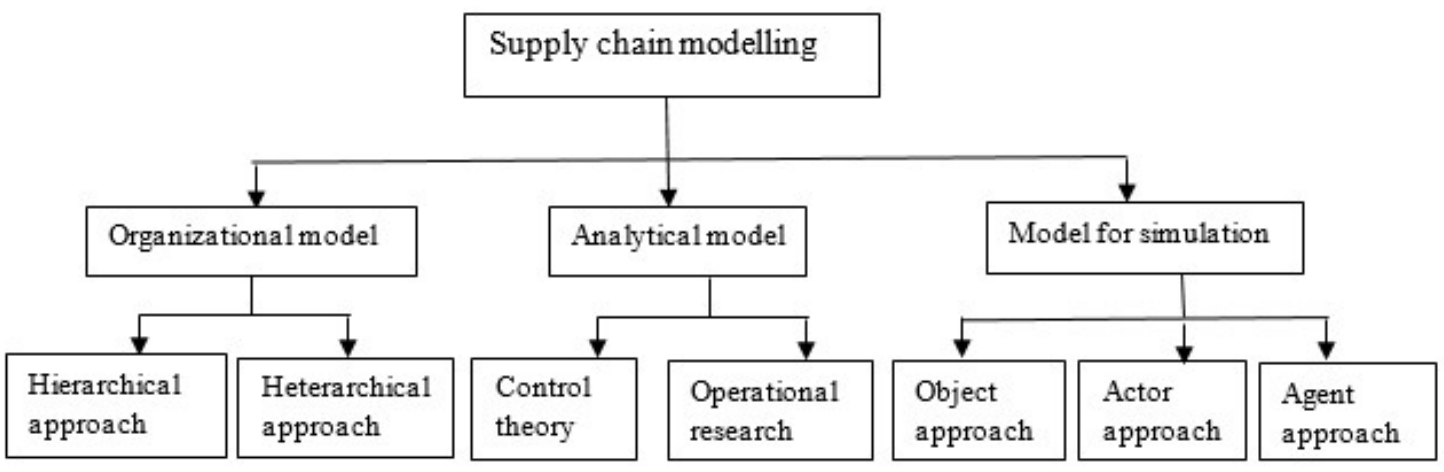

Fig 1: Design of logistic chain models [1]

\section{A. Organizational models}

Modeling approaches, which stem from the organization's theory of organization, represent the organization from its entities, activities, processes, functions, structure and behavior Fig.2.

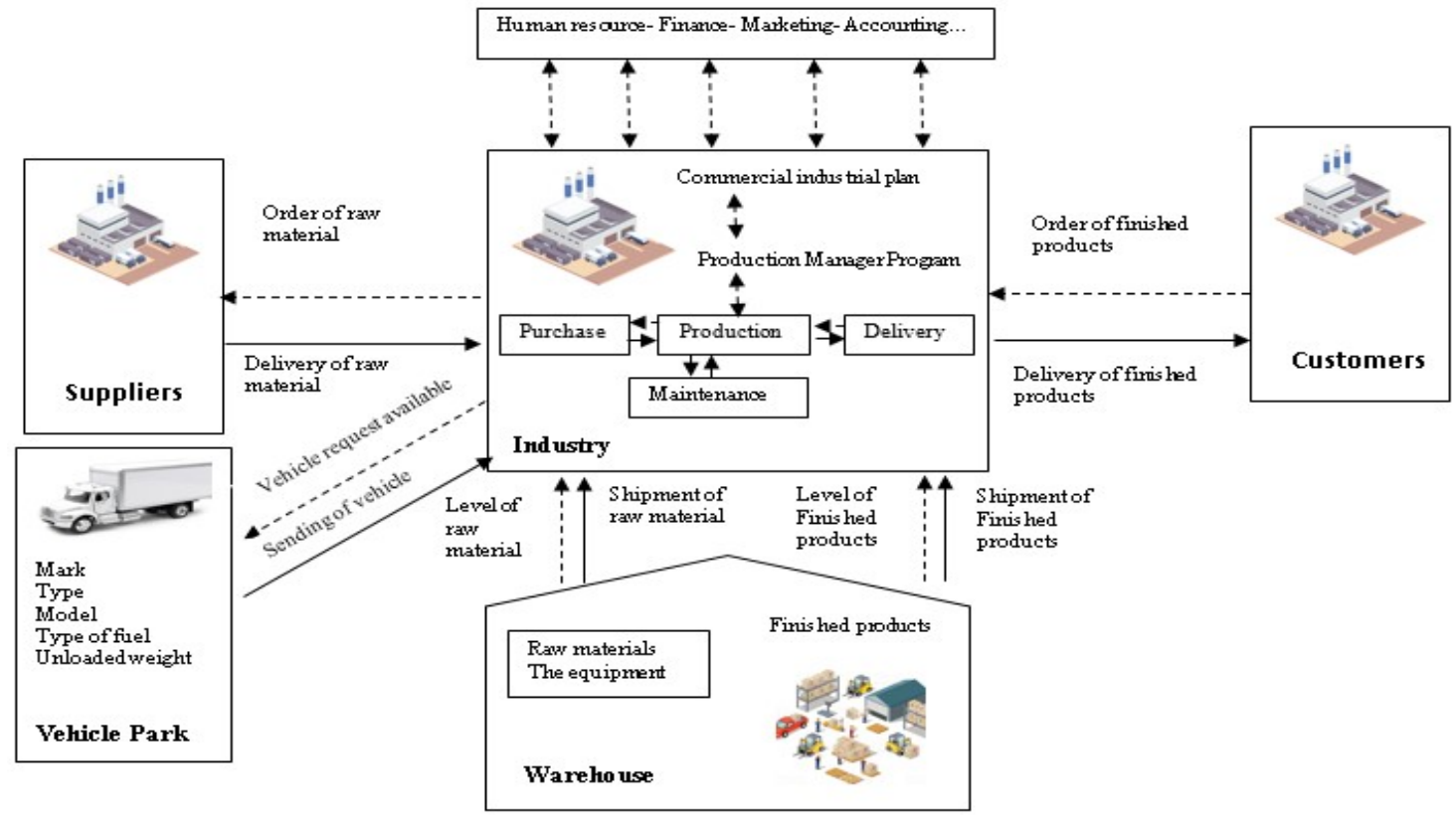

Fig.2: Organizational presentation of a supply chain

There are many so-called "organizational" models, which are described by [3] and [4] according to hierarchical or heterarchical approaches

\section{- Hierarchical approach}

The Cartesian approach, also called "structured", are based on the techniques of the descending decomposition of a function into sub-functions, until reaching a level of sufficient granularity to apprehend the complexity of a system [5].

However, this approach takes little account of interactions between subsystems. Among the best known formalisms we find Structured Analysis and Design Technique"SADT" and Structured Analysis for Real Time "SA-RT": 


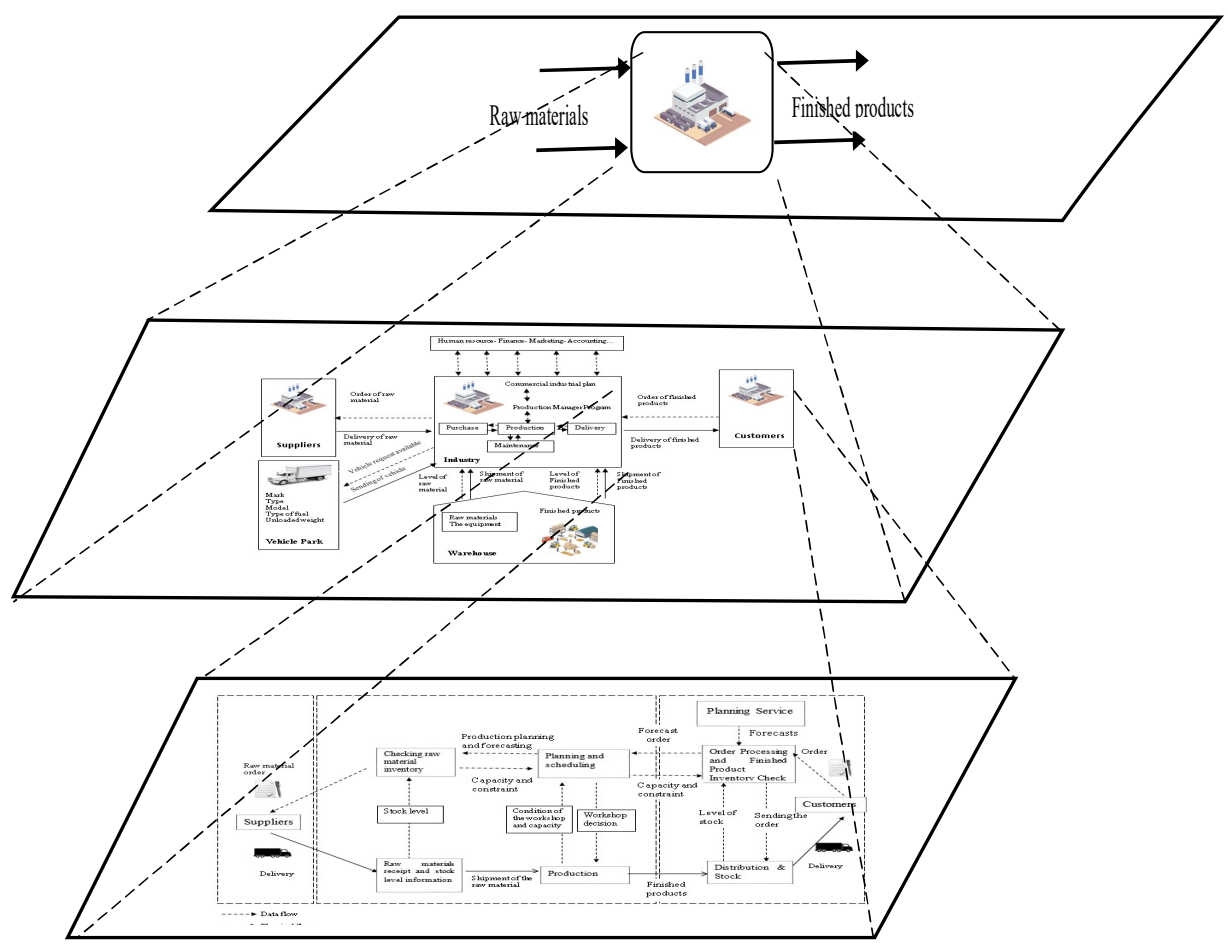

Fig 3: The SADT formalism

Systemic approaches emerged in the 1980s in the face of the growing complexity of organizations and their environments [6]

Unlike the Cartesian approach which dissociates and decomposes, the systemic approach associates and brings together in order to take into account the global vision of a problem

- Heterarchical approach

Heterarchical vision represents the evolution of architectures in manufacturing systems characterized by the autonomy and interaction between components [7]

However, heterarchical approaches offer a static representation of the organization of the system, hence the need for dynamic analysis tools. Trentesaux proposes four heterarchical approaches that would be "the processbased approach, the holonic approach, the emerging approaches, and the multi-agent approach" [8].

The process approach considers the company as a process in itself. It represents the organization as a set of entities, in interaction, for the realization of processes and / or activities [9].

Among these approaches, we find the model "SCOR" (Supply Chain Operation Reference)

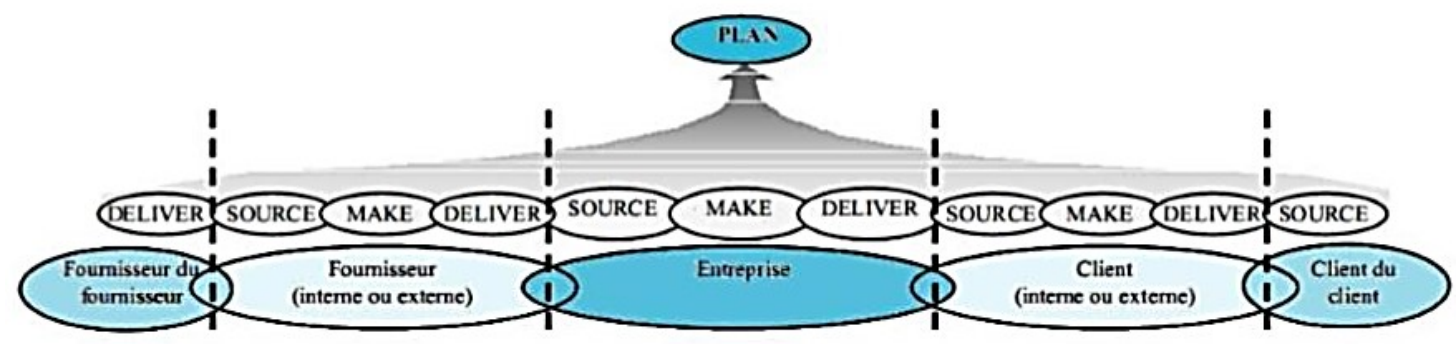

Fig 4: SCOR model (Supply Chain Council, 2005)

\section{B. Analytical models}

From the mathematical school, analytical models represent the supply chain from a quantitative perspective. The scientific community to solve these problems, which would be «The Theory of Control and Operational Research», adopts two main approaches [10]. 
On the one hand, "control theory" models the supply chain from differential equations and uses transformation analysis to understand its dynamics over time. This method is dynamic but relies on assumptions of linearization of behavior hence the need to adapt the conditions of the real model. However, it is unable to represent all logistics chains in all their complexity. A review of work on this approach is presented in [11]

On the other hand, "operational research" is based on optimization theories, game theory, statistics, and algorithms applies to linear and nonlinear systems. This method does not take time into account, which makes modeling the dynamic behavior of entities difficult to express. A review of work on this approach is presented in [12]

\section{Models for simulation}

The simulation makes it possible to exploit a model, the latter having to react and react in a similar way to the real system, [13], In order to know the dynamic behavior of the model and to predict its future behavior [14].

From a more computerized point of view, Treuil et al., Define simulation as "the activity during which, according to a protocol and with a precise objective, a simulator is used to change the inputs of a dynamic model , Execute it, and collect its outputs. Any model written according to the meta-model associated with the simulator and containing at least one input parameter can lend itself to this simulation process " [15] .

According to Fig 5 Cassandras and Lafortune propose a classification of the models for the simulation along the time axis (continuous or discrete) and the nature of variables and parameters (deterministic or stochastic) [16]

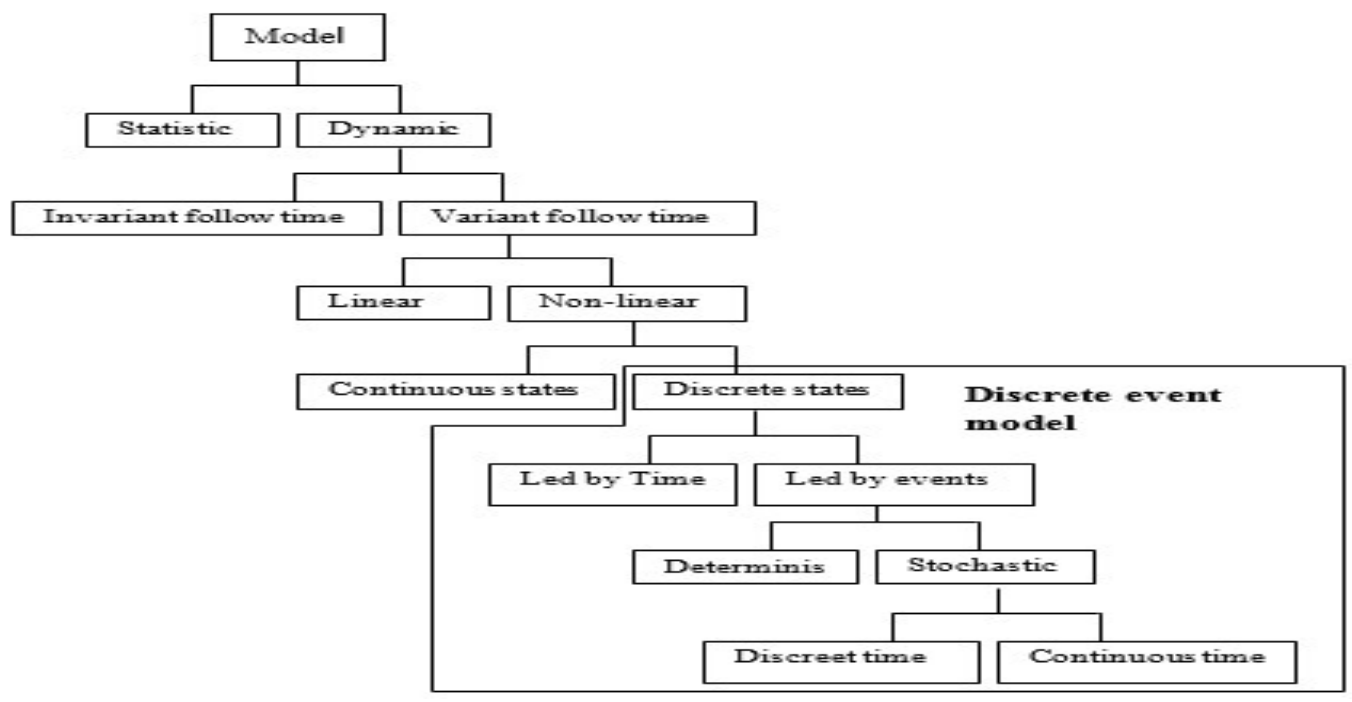

Fig5: Classification of models for simulation

According to Labarthe, the majority of logistic chain simulation work is based on discrete event models. These models are adapted to the dynamic characteristics and nonlinearities of the behaviors of such complex systems. The use of simulation as an analytical tool promotes an understanding of the behavior of the system in relation to the temporal component [17].

According to the reference [18], the simulation can have several final objectives influencing the choice of the modeling and simulation technique that will be used. These objectives are listed in the following table:

\begin{tabular}{|c|c|}
\hline \multicolumn{2}{|c|}{ Table 1 : Final objectives of the simulation } \\
\hline $\begin{array}{c}\text { Validation, Evaluation, } \\
\text { Verification }\end{array}$ & $\begin{array}{c}\text { The purpose of the simulation is to test a hypothesis of the model } \\
\text { of the reference system, to verify it or to accredit the theory used } \\
\text { to construct it. }\end{array}$ \\
\hline $\begin{array}{c}\text { Communication, Training, Visualization } \\
\text { Understanding, Exploration, } \\
\text { Explicitation }\end{array}$ & $\begin{array}{c}\text { The simulation aims to show and share the model of the dynamics } \\
\text { of the reference system. }\end{array}$ \\
\hline $\begin{array}{c}\text { Control, Action, Piloting } \\
\text { refence system by considering the model as a miniature replica, } \\
\text { which can be studied more easily. }\end{array}$ \\
\hline
\end{tabular}




\begin{tabular}{|l|l|}
\hline & control that will affect the (real) state of the reference system. \\
\hline Forecasting, Prediction, Anticipation & $\begin{array}{c}\text { The simulation is used to predict the possible evolutions of the } \\
\text { reference system according to specific evolutions or disturbances. }\end{array}$ \\
\hline
\end{tabular}

\section{CONCLUSION}

Optimizing the logistics chain means mastering the various operations carried out (supply, production, delivery, transport, etc.) in order to understand the dynamic nature of the logistics chain favoring the study of coordination and for example the interaction of transport with the various actors in the chain.

The literature review of logistic chain models - organizational models, analytical models and models for simulation - shows the presence of several research carried out in recent years and yet the need for improvement and improvement is still necessary.

The design of organizational approaches makes it possible to diagnose and master in a thorough way the dynamic interactions of the various decision makers of transport of the goods and the actors of the logistic chain taking into account external constraints and influences.

\section{REFERENCES}

[1] Olivier Labarthe, modélisation et simulation orientées agents de chaînes logistiques dans un contexte de personnalisation de masse : modèles et cadre méthodologique, Marseille: Université Paul Césanne, , 2006.

[2] A. S. J. a. Z. O. DOLGUI, " Supply Chain Optimisation product/process design, facility location and flow control," springer, 2005.

[3] T. Monteiro, Conduite distribuée d'une coopération, entre entreprises, le cas de la relation donneurs d'ordres - fournisseurs, France: Thèse de doctorat, Institut National Polytechnique de Grenoble, 2001.

[4] J. Frayret, Conceptual Framework to Operate Collaborative Manufacturing Networks, thèse de doctorat, Université Laval, 2002.

[5] H. R. A. C. R. Tardieu, La méthode Merise : Principes et outils, Tome 1, Les Editions d'Organisation, 1989.

[6] J. Le Moigne, La théorie du système général, théorie de la modélisation, Presse universitaires de France, 1977.

[7] D. B. N. W. H. Dilts, "The evolution of control architectures for automated manufacturing Systems," Journal of Manufacturing Systems, vol. 10, no. 1, pp. 79-93, 1991.

[8] D. Trentesaux, Pilotage hétérarchique des systèmes de production, Université de Valenciennes et du HainautCambrésis, 2002.

[9] N. Duffie, "Synthesis of heterarchical manufacturing Systems," Computers in Industry, vol. 14, no. 1-3, pp. 167-174, 1990.

[10] H. S. R. R. R. a. C. S. Parunak, DASCh: Dynamic Analysis of Suppfy Chains, Center for Electronic Commerce Final Report, 1999.

[11] M. L. L. Ortega, "Control theory applications to the production-inventory problem: a review," International Journal of Production Research, vol. 42, no. 1, pp. 2303-2322, 2004.

[12] J. P. P. Geunes, "Network Optimisation in Supply Chain Management and Financial Engineering: An Annoted Bibliography," Networks, vol. 42, no. 2, pp. 66-84, 2003.

[13] P. Queau, Éloge de la simulation : de la vie des langages à la synthèse des images, Paris: Champ Vallon, 1986.

[14] J. P. D. G. J. Claver, Gestion de flux en entreprise: modélisation et simulation, Hermès, 1996.

[15] J. D. A. Z. J. Treuil, Modélisation et simulation à base d'agents: exemples commentés, outils informatiques et questions théoriques, Dunod, 2008.

[16] C. L. S. Cassandras, Introduction to discrète event Systems, Boston: Kluwer Académie Publishers, 1999.

[17] O. Labarthe, Modélisation et simulation orientées agents de chaînes logistiques dans un contexte de personnalisation de masse : modèles et cadre méthodologique, Thèse de doctorat en cotutelle (Université Paul Cézanne et Université Laval), , 30 octobre 2006.

[18] J. D. A. Z. J. Treuil, Modélisation et simulation à base d'agents: exemples commentés, outils informatiques et questions théoriques, Dunod, 2008.

[19] O. a. Z. G. MIN, "Supply chain modelling: past, présent and future," Computers \& Industrial Engineering, vol. 43, no. 1-2, pp. 231$249,2002$.

[20] F. G. E. Cottet, Systèmes temps réel de contrôlecommande, Ed. Dunond, 2005.

[21] E. Bonabeau, "Agent-based modelling: Methods and techniques for simulating human systems," Proceedings of the National Academy of Sciences, vol. 99, no. 3, 2002. 
International Journal of Innovations in Engineering and Technology (IJIET)

http://dx.doi.org/10.21172/ijiet.84.011

[22] J. Epstein, Generative social science: Studies in agent-based computational modelling, Princeton: Princeton University Press, 2011.

[23] J. H. K. \&. S. F. Xu, " Simulation of regional freight movement with trade and transportation multinetworks," Transportation Research Record, vol. 1854, pp. 152-161, 2003. 